\title{
Research productivity across different ophthalmic subspecialties in the United States
}

\author{
Assaf Gershoni ${ }^{1,2^{*}}$ (D), Igor Vainer ${ }^{3}$, Olga Reitblat ${ }^{1,2}$, Francis B. Mimouni ${ }^{4}$, Eitan Livny ${ }^{1,2}$, Eytan Z. Blumenthal ${ }^{3}$,
} Rita Ehrlich ${ }^{1,2}$ and Michael Mimouni ${ }^{3}$

\begin{abstract}
Background: The purpose of this study was to compare the h-index, and subsequently the research productivity, among different ophthalmic subspecialties in the United States.

Methods: A cohort of over 15,000 academic ophthalmologists residing in the United States (US) was identified out of the physician list of the American Academy of Ophthalmology. Of them, 1000 ophthalmologists with at least one publication were randomly retrieved, 100 in each of the following 10 subspecialties: cataract, cornea/external disease, glaucoma, medical retina, neuro-ophthalmology, pediatric ophthalmology, plastic/reconstructive ophthalmology, refractive surgery, retina/vitreous surgery and uveitis. Data collected included: number of published papers, h-index score, annual increase in h-index and the mean number of authors on each paper.

Results: The mean h-index amongst all subspecialties was $9.87 \pm 13.90$, and the mean average annual increase in $\mathrm{h}$ index was $0.22 \pm 0.21$. The mean number of papers published was $37.20 \pm 80.08$ and the mean number of authors on each paper was $3.39 \pm 0.84$. Uveitis was the most prolific subspecialty in mean number of papers (74.78 \pm 131.37), in mean $h$-index $(16.69 \pm 20.00)$ and in mean annual increase in $h$-index $(0.35 \pm 0.28)$. The least fertile subspecialty with regards to research was cataract with $11.06 \pm 27.65$ mean number of papers, a mean h-index of $3.89 \pm 5.84$, and a mean annual increase in h-index of $0.11 \pm 0.11$.

Conclusions: This study describes the research productivity in each ophthalmic subspecialty in the US, thus providing information on the research performance of each field and on the expected academic accomplishments within it.
\end{abstract}

Keywords: Research productivity, H-index, Ophthalmic subspecialties, Academia

\section{Background}

The h-index was introduced in 2005 by prof. J.E. Hirsch to quantify the importance, significance and broad impact of a scientist's cumulative research contribution [1]. The $h$-index reflects the number $h$ of papers a researcher is a co-author on, each of which has been cited at least $\mathrm{h}$ times in other papers. Today it is widely accepted as the standard of scientometrics of an individuals' research impact, and was further tailored to predict

\footnotetext{
* Correspondence: Gershoni.assaf@gmail.com

${ }^{1}$ Department of Ophthalmology, Rabin Medical Center - Beilinson Hospital, Petah Tikva, Israel

${ }^{2}$ Sackler Faculty of Medicine, Tel Aviv University, Tel Aviv, Israel

Full list of author information is available at the end of the article
}

young scientists' potential [2]. Furthermore, the h-index is used as an assessment tool in many universities and academic medical centers by committees for recruitment, promotion, tenure and awarding of grants. Its application in medicine has been recently explored in various specialties [3-12].

Ophthalmology encompasses a variety of activities which a physician can engage in: clinical medical care, surgical care, teaching and research. Ophthalmology residents interested in an academic career should be given the opportunity to get accurate information about the potential for research advancement and academic promotion of a given subspecialty they consider to fellow in. As there is a proven correlation between $\mathrm{h}$-index,

(c) The Author(s). 2019 Open Access This article is distributed under the terms of the Creative Commons Attribution 4.0 International License (http://creativecommons.org/licenses/by/4.0/), which permits unrestricted use, distribution, and reproduction in any medium, provided you give appropriate credit to the original author(s) and the source, provide a link to the Creative Commons license, and indicate if changes were made. The Creative Commons Public Domain Dedication waiver (http://creativecommons.org/publicdomain/zero/1.0/) applies to the data made available in this article, unless otherwise stated. 
academic rank and grant funding [3, 4, 7, 11, 13-19], knowledge of the mean h-index in each field in ophthalmology and thus of the possibility of expected academic accomplishments might be factored in their decisionmaking process.

The purpose of this study was to describe and compare the research productivity (as measured by the proxy h-index) of various ophthalmic subspecialties in the United States (US). We hypothesized that authors from various sub-specialties of ophthalmology have different h-indices. It was also to try and determine the factors possibly associated with the h-index such as authors' gender, total number of published papers, total number of citations, annual increase in h-index and number of authors on each paper. A last purpose was to determine the annual increase in $\mathrm{h}$-index and the factors related to it.

\section{Methods}

\section{Data acquisition}

A study cohort of over 15,000 ophthalmologists residing in the US was identified out of the physician list of the American Academy of Ophthalmology. Each ophthalmologist was assigned a subspecialty, as recorded on the American Academy of Ophthalmology website (www. aao.org, accessed: December 4, 2018). Out of this cohort, 100 ophthalmologists were chosen in each one of the following 10 subspecialties: cataract, cornea/external disease, glaucoma, medical retina, neuro-ophthalmology, pediatric ophthalmology, plastic/reconstructive ophthalmology, refractive surgery, retina/vitreous surgery and uveitis. A random drown of ophthalmologists within each subspecialty, using random number allocating, was performed. In order to be chosen for the study, each ophthalmologist had to be one with at least one scientific publication. Ophthalmologists with no publications were excluded. Data collection was stopped once reaching a list of 100 ophthalmologists within each subspecialty. Overall, we retrieved 1000 ophthalmologists for this study.

Data were collected using Harzing, A.W. (2007) Publish or Perish (www.harzing.com, London. United Kingdom) on December 2018, and were incorporated into an Excel spreadsheet (Microsoft, Inc., Seattle, WA). The authors' gender was obtained through a series of quests utilizing the Google search engine. The authors' names were combined with their sub specialty, while relying on an official source (Hospital profile, Private website, Advertisement with a photograph, etc.), and their gender was recorded.

\section{Study variables}

The primary outcome was to describe the research productivity by using the $\mathrm{h}$-index, across the above-mentioned various ophthalmic subspecialties in the United States. Other variables which were collected included: total number of published papers, total number of citations, annual

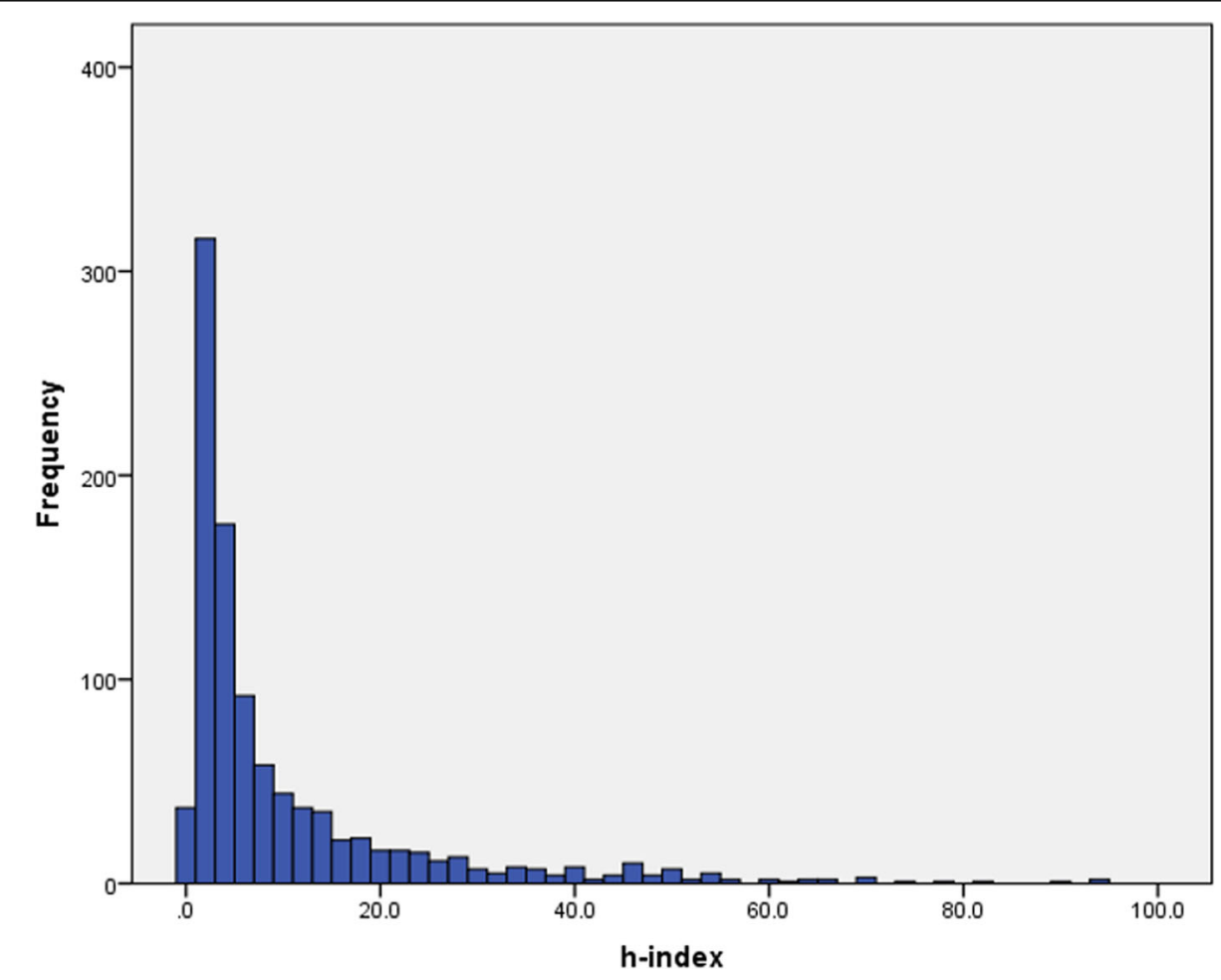

Fig. 1 The h-index score histogram of the entire cohort 


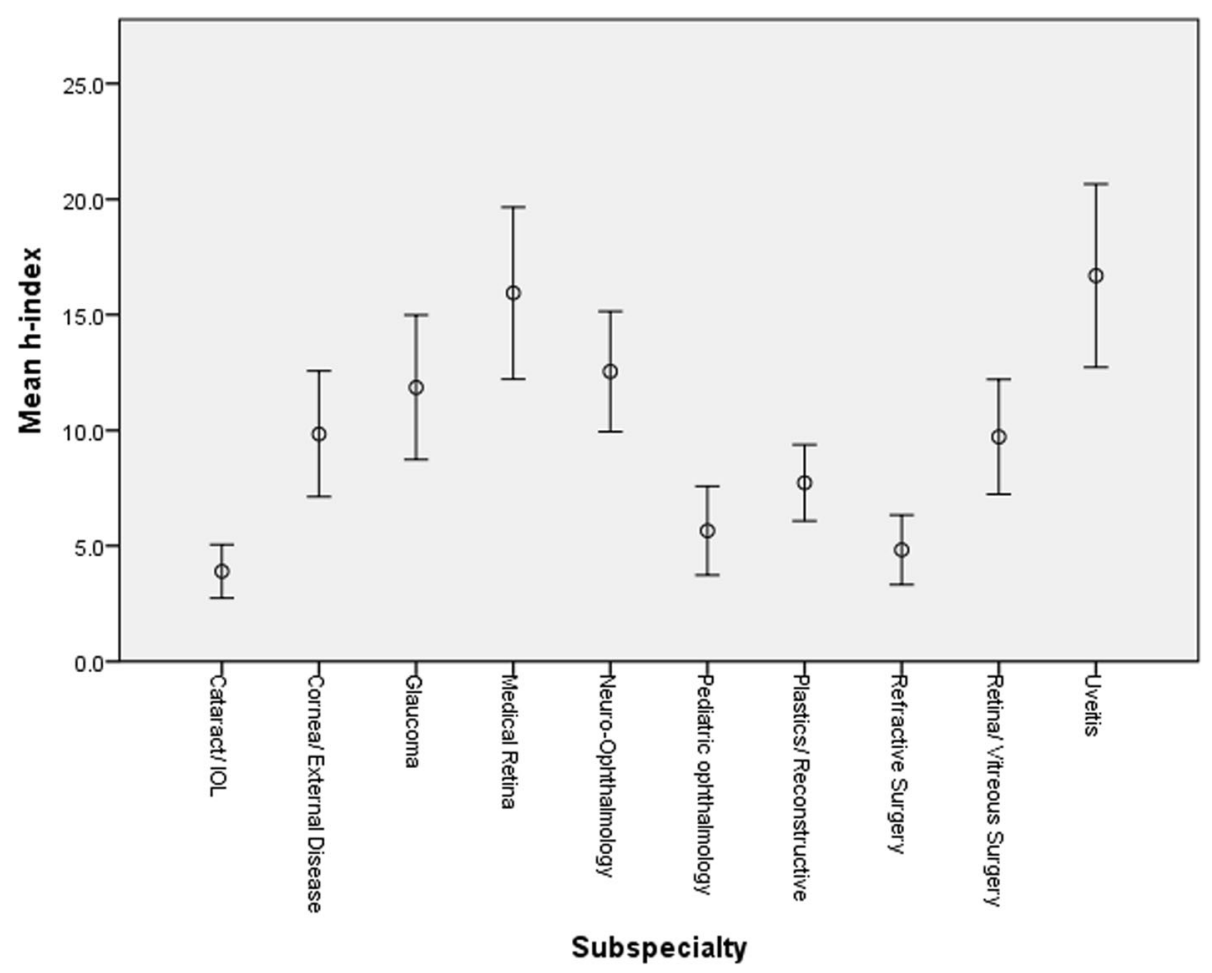

Fig. 2 The h-index score in each of the 10 ophthalmology subspecialties

increase in h-index, number of authors on each paper and the gender of the ophthalmologists who were retrieved.

\section{Statistical analysis}

Data were analyzed using the SPSS statistical software version 23.0 (SPSS, Cary, NC, US). Data are expressed as mean \pm SD. Statistical differences between groups were tested using a one-way analysis of variance (ANOVA) for normally distributed data and the Kruskal-Wallis test for non-normally distributed data. The Bonferroni correction was applied for multiple comparisons. The Pearson correlation was used to analyze the relationship between h-index and the number of citations, the number of authors per paper and the number of papers. A $P$-value of less than 0.05 was considered statistically significant.

\section{Results}

Figure 1 depicts the frequency of the h-index score in the entire cohort. Figure 2 presents the mean h-index in each subspecialty. The mean h-index among all subspecialties was $9.87 \pm 13.90$ (Table 1). The mean number of papers published in the entire study group was $37.20 \pm$

Table 1 Research productivity comparison of ophthalmic subspecialties

\begin{tabular}{lllll}
\hline Parameter & Num. of papers & Num. of authors for each paper & h-index & Average annual increase in h-index \\
\hline Cataract/IOL & $11.06 \pm 27.65$ & $3.33 \pm 1.02$ & $3.89 \pm 5.84$ & $0.11 \pm 0.11$ \\
Cornea/External Disease & $35.71 \pm 63.90$ & $3.56 \pm 0.75$ & $9.84 \pm 13.70$ & $0.24 \pm 0.22$ \\
Glaucoma & $45.15 \pm 110.97$ & $3.56 \pm 0.68$ & $11.86 \pm 15.73$ & $0.25 \pm 0.22$ \\
Medical Retina & $55.94 \pm 85.93$ & $3.52 \pm 0.79$ & $15.94 \pm 18.74$ & $0.31 \pm 0.25$ \\
Neuro-Ophthalmology & $56.55 \pm 98.71$ & $3.18 \pm 0.75$ & $12.54 \pm 13.10$ & $0.23 \pm 0.17$ \\
Pediatric Ophthalmology & $19.93 \pm 51.98$ & $3.41 \pm 0.86$ & $5.65 \pm 9.70$ & $0.15 \pm 0.14$ \\
Plastics/Reconstructive & $28.21 \pm 46.34$ & $3.08 \pm 0.79$ & $7.73 \pm 8.32$ & $0.21 \pm 0.15$ \\
Refractive Surgery & $14.17 \pm 38.70$ & $3.13 \pm 1.07$ & $4.82 \pm 7.62$ & $0.13 \pm 0.13$ \\
Retina/Nitreous Surgery & $30.53 \pm 54.14$ & $3.50 \pm 0.75$ & $9.72 \pm 12.57$ & $0.25 \pm 0.21$ \\
Uveitis & $74.78 \pm 131.37$ & $3.62 \pm 0.71$ & $16.69 \pm 20.00$ & $0.35 \pm 0.28$ \\
Entire cohort & $37.20 \pm 80.08$ & $3.39 \pm 0.84$ & $9.87 \pm 13.90$ & $0.22 \pm 0.21$
\end{tabular}

Values are mean \pm SD 


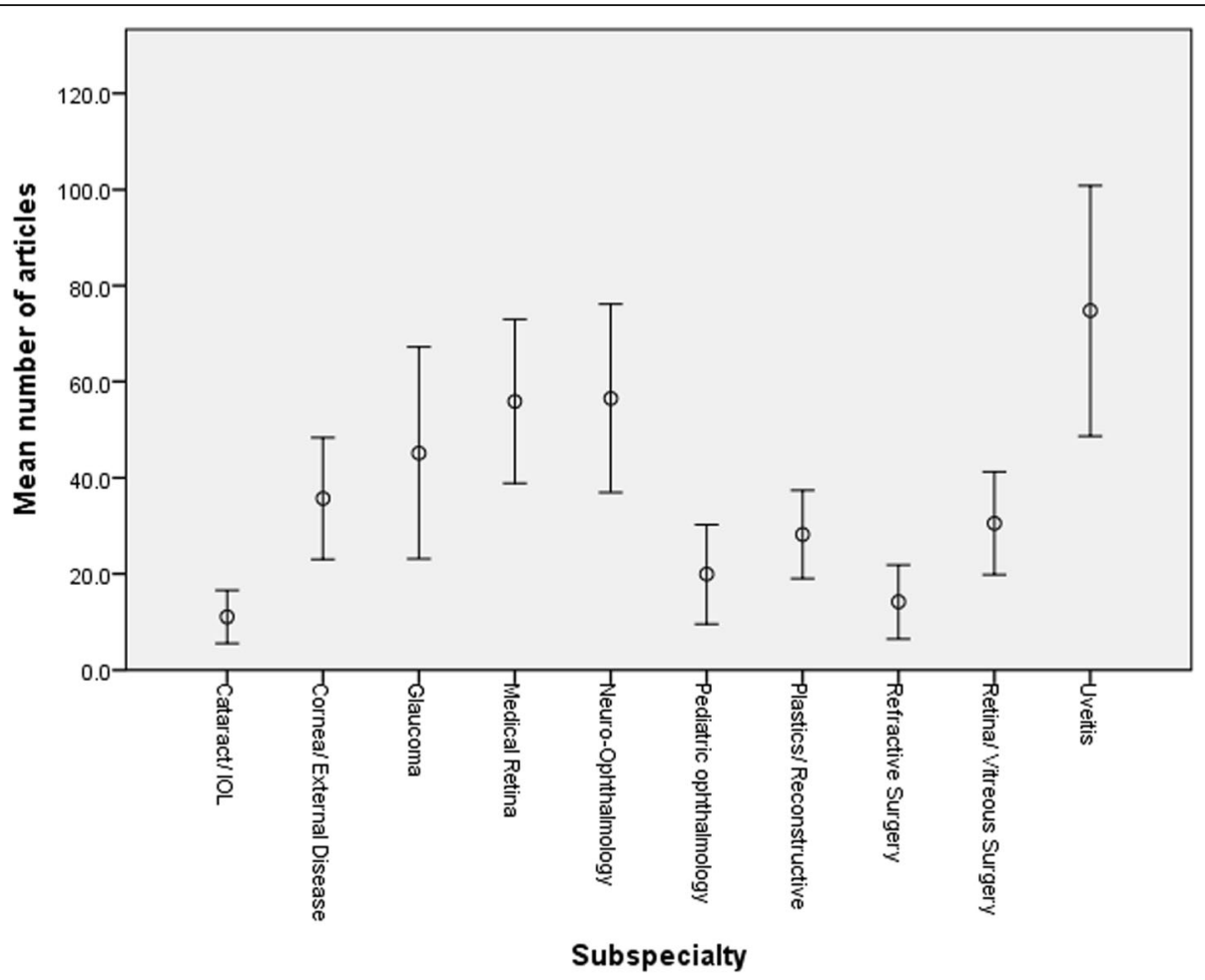

Fig. 3 Number of articles for each of the 10 ophthalmology subspecialties

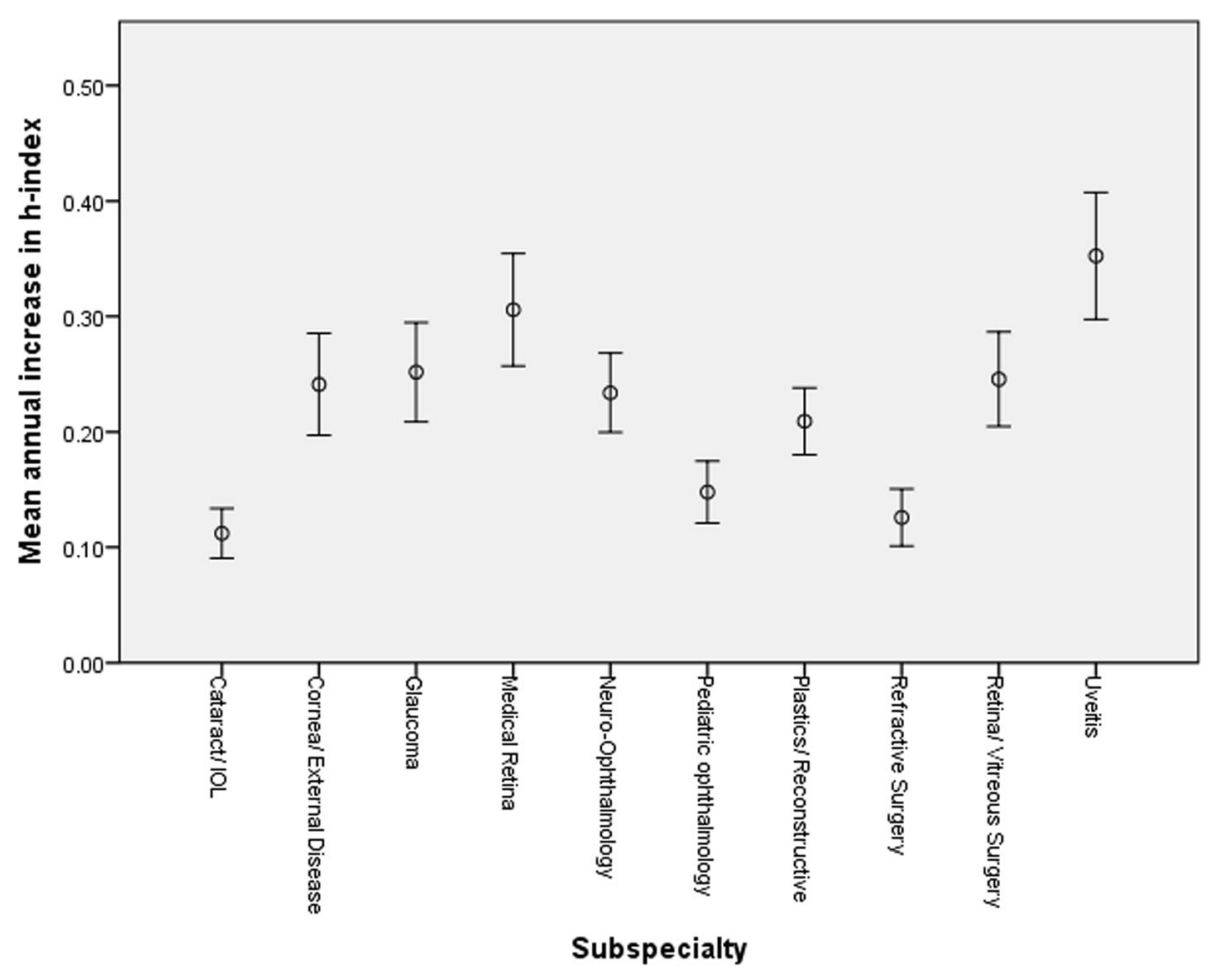

Fig. 4 Average annual increase in the individual h-index score for each of the 10 ophthalmology subspecialties 


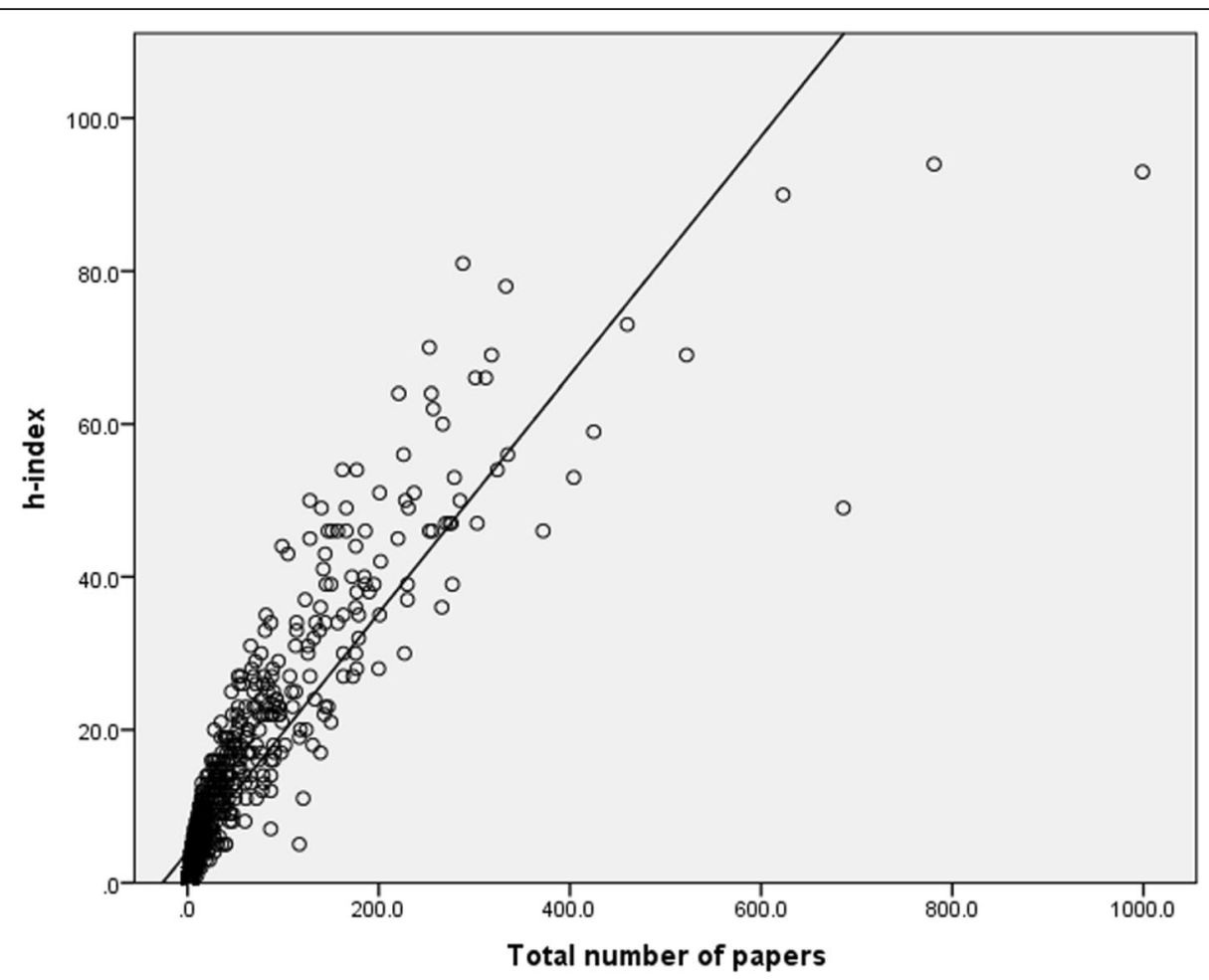

Fig. 5 Correlation between the number of papers and the h-index

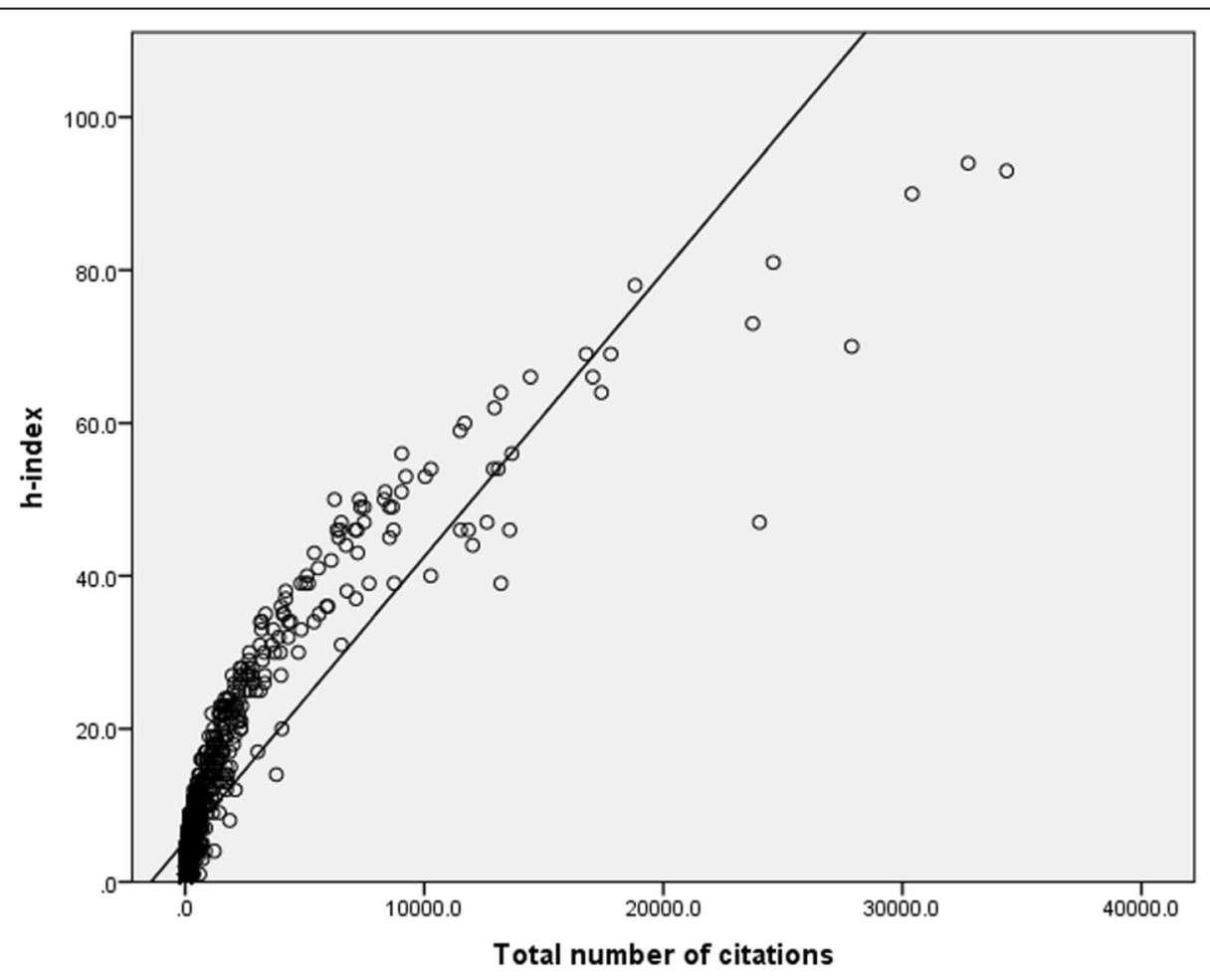

Fig. 6 Correlation between the number of citations and the h-index 
80.08 and the mean number of authors on each paper was $3.39 \pm 0.84$ (Table 1). Figure 3 shows the mean number of papers an author published in each subspecialty. The mean average annual increase in h-index was $0.22 \pm 0.21$ (Table 1) and is shown for each subspecialty in Fig. 4.

Uveitis was, the most prolific subspecialty in mean number of papers $(74.78 \pm 131.37, P<0.001)$, in mean $\mathrm{h}$ index $(16.69 \pm 20.00, P<0.001)$ and in mean annual increase in h-index $(0.35 \pm 0.28, P<0.001)$. The least fertile subspecialty with regards to research was cataract with a mean number of papers of $11.06 \pm 27.65$ and a mean hindex of $3.89 \pm 5.84$.

The mean number of authors on each paper ranged between 3.08 and 3.62 and was not found to be correlated with the h-index score $(r=0.083, P=0.008)$. As expected, a significant high correlation was found between the number of papers published and the h-index score $(r=0.898, P<0.001$, Fig. 5$)$, and between the number of citations and the h-index score $(r=0.893$, $P<0.001$, Fig. 6).

The gender distribution of the ophthalmologists retrieved in each subspecialty is presented in Fig. 7.
Figure 8 and Table 2 present a comparison of the mean $\mathrm{h}$-index between genders in each individual ophthalmology subspecialty. In a comparison between genders in the entire cohort the male ophthalmologists exhibited a significantly higher mean h-index than the female ones (10.93 and 7.15, respectively, $P<0.001$ ). There was a trend to higher mean h-index in males than in females in all subspecialties, which reached statistical significance in the fields of cornea/external disease, glaucoma, neuroophthalmology and pediatric ophthalmology (Table 2).

\section{Discussion}

The purpose of this study was to compare the h-index (a proxy measurement of research productivity) across various ophthalmology subspecialties in the United States. To the best of our knowledge, no such study has been conducted to date.

In 2005, prof. Jorge Hirsch introduced the h-index as an alternative to other scientific performance indices, such as number of publications, average number of citations and sum of all citations, in order to quantify the importance, significance and broad impact of a scientist's cumulative research contributions [1].

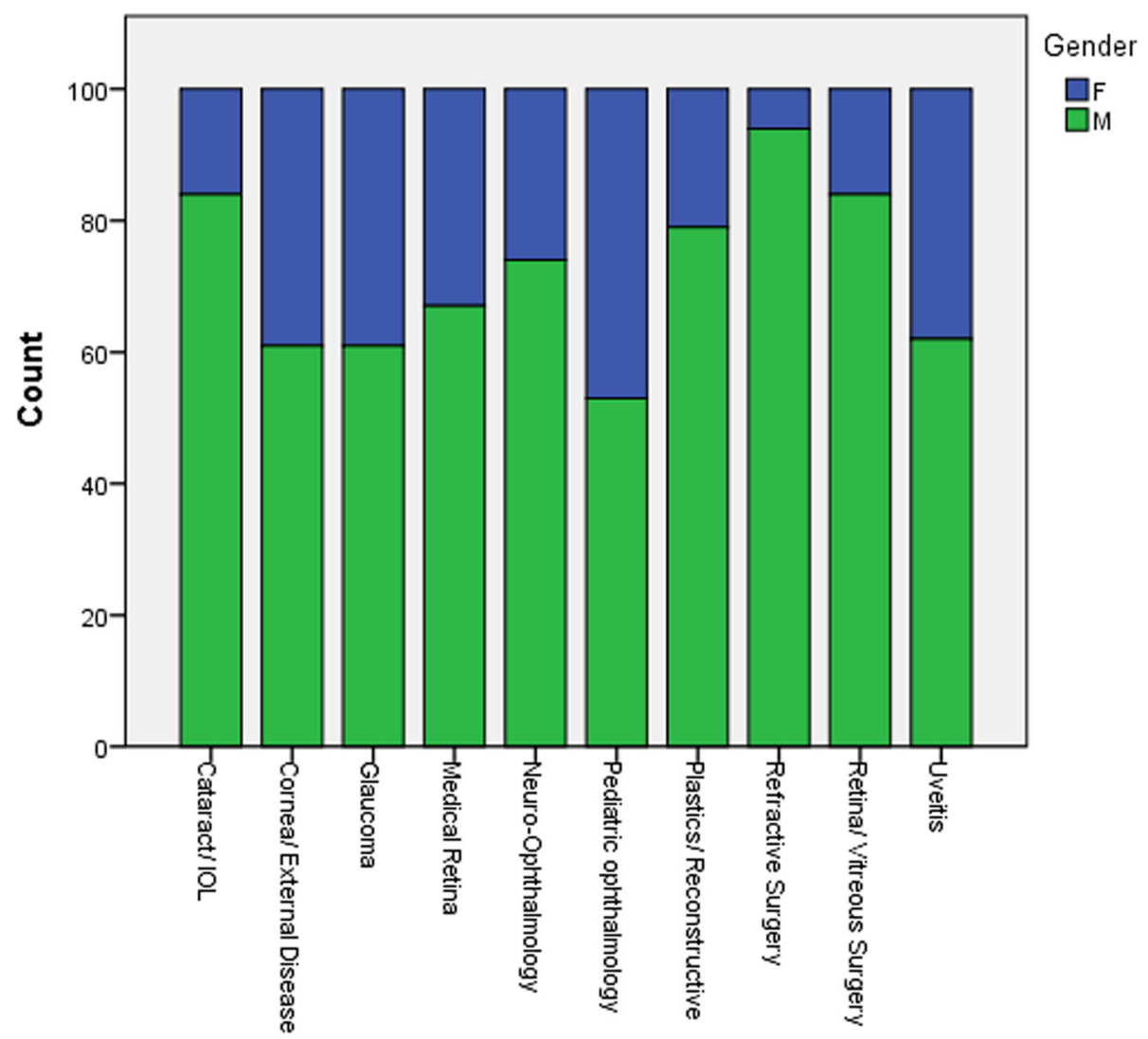

Subspecialty

Fig. 7 Distribution of genders in each of the 10 ophthalmology subspecialties 


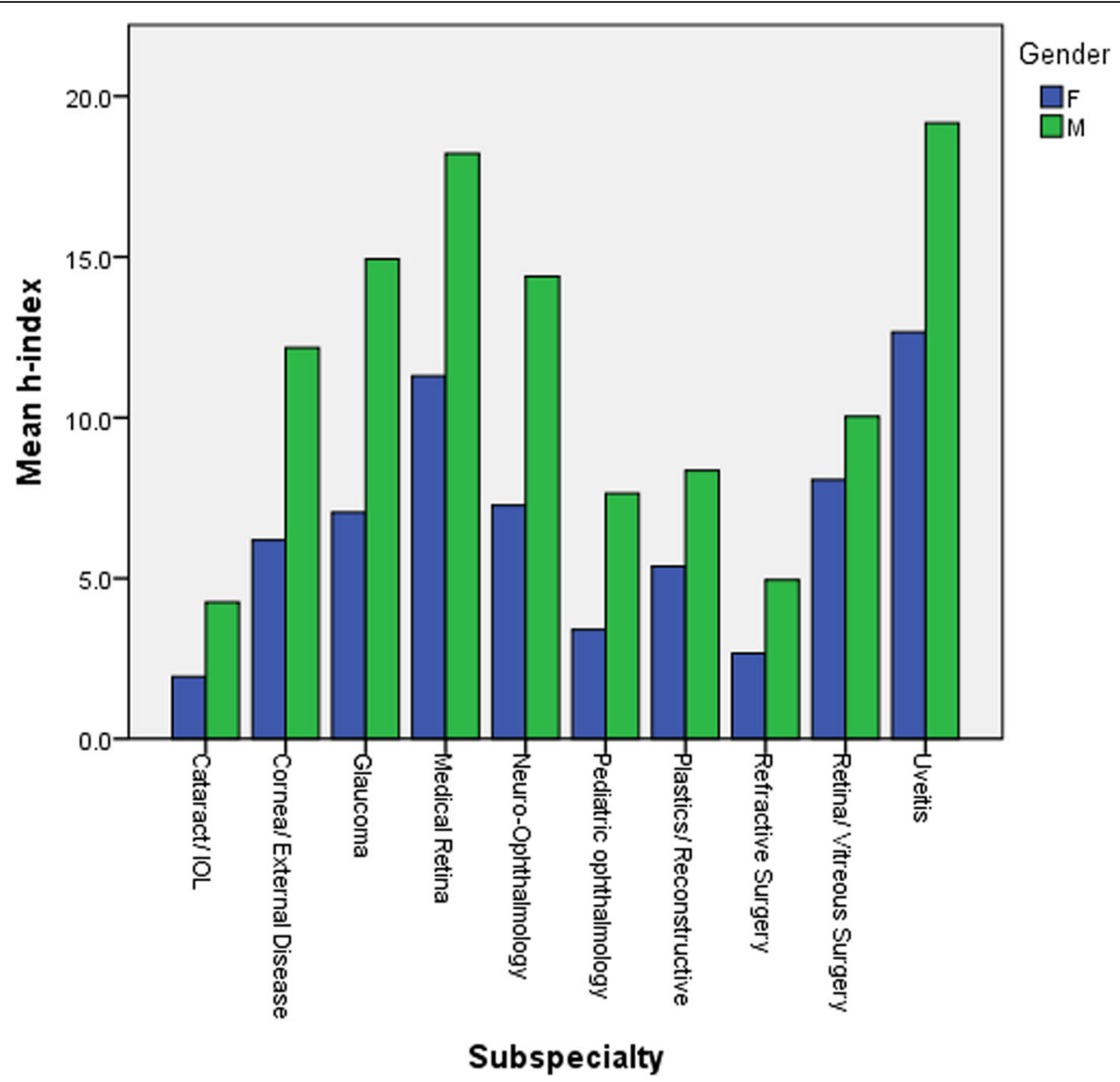

Fig. 8 Comparison of the mean h-index between genders in each of the 10 ophthalmology subspecialties

The $\mathrm{h}$-index reflects the number $\mathrm{h}$ of papers a researcher is a co-author on with at least $\mathrm{h}$ citations in other articles. It is widely accepted throughout the scientific community because it quantifies both the author's scientific productivity and the cumulative

Table 2 Comparison of the mean h-index between genders in each individual ophthalmology subspecialty

\begin{tabular}{llll}
\hline Subspecialty & Males & Females & $P$ \\
\hline Entire cohort & $10.93 \pm 14.78$ & $7.15 \pm 10.94$ & $<0.001$ \\
Cataract/IOL & $4.26 \pm 6.28$ & $1.94 \pm 1.18$ & 0.145 \\
Cornea/External Disease & $12.18 \pm 16.21$ & $6.18 \pm 7.14$ & 0.032 \\
Glaucoma & $14.93 \pm 18.69$ & $7.05 \pm 7.33$ & 0.014 \\
Medical Retina & $18.22 \pm 19.15$ & $11.30 \pm 17.23$ & 0.082 \\
Neuro-Ophthalmology & $14.39 \pm 13.59$ & $7.27 \pm 9.99$ & 0.016 \\
Pediatric Ophthalmology & $7.64 \pm 12.49$ & $3.40 \pm 4.09$ & 0.029 \\
Plastics/Reconstructive & $8.35 \pm 8.74$ & $5.38 \pm 6.14$ & 0.147 \\
Refractive Surgery & $4.96 \pm 7.83$ & $2.67 \pm 1.97$ & 0.478 \\
Retina/Vitreous Surgery & $10.04 \pm 13.12$ & $8.06 \pm 9.28$ & 0.568 \\
Uveitis & $19.16 \pm 21.04$ & $12.66 \pm 17.71$ & 0.115 \\
\hline
\end{tabular}

Values are mean \pm SD impact of his work. Furthermore, Poynard et al. demonstrated that a high h-index was associated with true conclusions, methodological quality of trials and positive predictive values [20]. It has even been shown that the h-index, as a measure of scientific interest, appears to be a reflection of the true impact of human diseases in medicine [21]. In addition, not only is the h-index a score reflecting one individual's lifetime work, but it has been further implemented to identify the research strength of institutions and to measure their academic productivity [22].

However, the h-index has its downsides as it can be inflated with self-citations [23] and may be discriminatory of epistemological beliefs and methodological preferences [24]. It can also act as a stressor and a source for burnout symptoms to young researchers who have yet to build their own, high h-index. In contrast, a high hindex may be reassuring for scientists and may become an important motivational factor for further, high quality research [25].

In this study, we compared the research productivity in 10 subspecialties of ophthalmology: cataract, cornea/external disease, glaucoma, medical retina, neuro-ophthalmology, 
pediatric ophthalmology, plastic/reconstructive ophthalmology, refractive surgery, retina/vitreous surgery and uveitis. The h-index score as well as the number of published papers were highest in uveitis followed by neuro-ophthalmology and medical retina. We speculate that, since these three fields are not surgical, they may grant more time to immerse in the minutiae of research. Theoretically, since these three fields complement other fields in medicine such as internal medicine and rheumatology with regards to uveitis, internal medicine with regards to medical retina and neurology and neurosurgery with regards to neuro-ophthalmology, they also might open the way to more collaboration with other practitioners, and hence more research opportunities. Against the latter theory is the lack of correlation that we found between mean number of authors and h-index. The mean h-index in uveitis was 16.69 and by comparison, in cataract the mean hindex score was 3.89 which was the lowest of all subspecialties. The other two subspecialties besides cataract with the lowest h-index, average annual increase in h-index and number of papers were pediatric ophthalmology and refractive surgery. Importantly, two of these subspecialties are essentially surgical ones, and possibly the most rewarding financially. Thus we speculate that such a financial incentive might harm academic motivation and performance. Regarding the annual increase in h-index, uveitis still ranked first with a mean increase of 0.35 to the h-index score annually and medical retina ranks second with 0.31 .

Nevertheless, in terms of ophthalmology, this superiority in publication indices does not necessarily reflect medical and social impact, but only the scope of academic activity. This can be influenced by other factors, such as spare time for research, economic motives and other academic and medical disciplines. For example, as mentioned above, uveitis, medical retina and neuroophthalmology are all related to other medical specialties. Thus, the potential for publication and citation in these fields is beyond the bounds of ophthalmology journals; therefore, expanding academic productivity, but not representing their clinical centrality in ophthalmology.

As expected, a significant correlation was found between the number of papers and the $\mathrm{h}$-index score and between the number of citations and the h-index score.

Another interesting aspect which was looked at was the gender distribution in each subspecialty. In a recent publication [26], we showed that despite an overall increase in the contribution of women to the field of ophthalmology, contributions to articles published in subspecialty ophthalmology journals and the proportion of women listed as last authors on overall articles published in ophthalmology journals are still low. In this study, we also found that that in all subspecialties there was a male predominance. In addition, the mean h-index of the male authors was significantly higher than that of the female ones in the entire cohort (Table 2), as well as in every subspecialty
(Table 2, Fig. 8). Nevertheless, the recent increase in the contribution of women to the field of ophthalmology will hopefully begin to show its markings in the near future.

This study has several limitations. First, individuals in each field were chosen randomly, and even though the sample size was quite large, the samples may not be, by chance, representative of the group they were extracted from. Second, the sample included only ophthalmologists that published at least one paper. Including clinicians who have not published any papers would have lowered the study measures regarding cumulative academic contribution (mean number of published papers, mean h-index score and mean annual increase in h-index). However, the decrease in each subspecialty might have been different, and thus, possibly modifying the outcomes.

Notwithstanding its limitations, this study is the first to compare the research productivity among major subspecialties of opthalmology. It may provide young scientist in search of a fertile field of academic ophthalmology an additional tool for evaluation.

\section{Conclusions}

In this study, we described the research productivity in different ophthalmic subspecialties in the US, providing, to the best of our knowledge for the first time, valuable information on the research performance of each field and on the expected academic accomplishments within it. As evident by the average h-index score and number of publications, we have found the highest academic productivity to be in uveitis followed by neuro-ophthalmology and medical retina.

\section{Abbreviation}

US: United States

\section{Acknowledgements}

Not applicable.

\section{Authors' contributions}

AG participated in the design of the study, collected the data, drafted the manuscript and read and approved the manuscript. IV participated in the design of the study, performed the statistical analysis, made revisions to the manuscript and read and approved the manuscript. OR collected the data, performed the statistical analysis, made revisions to the manuscript and read and approved the manuscript. FBM participated in the design of the study, helped to analyze the results, made revisions to the manuscript and read and approved the manuscript. EL participated in the design of the study, helped to analyze the results, made revisions to the manuscript and read and approved the manuscript. EZB participated in the design of the study, helped to analyze the results, made revisions to the manuscript and read and approved the manuscript. RE collected the data, helped to analyze the results, made revisions to the manuscript and read and approved the manuscript. MM conceived of the study, participated in its design and coordination, helped to draft the manuscript and read and approved the manuscript.

\section{Funding}

No funding was received.

Availability of data and materials

The datasets used and/or analysed during the current study are available from the corresponding author on reasonable request. 
Ethics approval and consent to participate

Not applicable.

\section{Consent for publication}

Not applicable.

\section{Competing interests}

The authors declare that they have no competing interests.

\section{Author details}

'Department of Ophthalmology, Rabin Medical Center - Beilinson Hospital, Petah Tikva, Israel. ${ }^{2}$ Sackler Faculty of Medicine, Tel Aviv University, Tel Aviv, Israel. 'Department of Ophthalmology, Rambam Health Care Campus, Haifa, Israel. ${ }^{4}$ Department of Neonatology, Shaare Zedek Medical Center, Jerusalem, Israel.

Received: 21 March 2018 Accepted: 9 October 2019

Published online: 01 November 2019

\section{References}

1. Hirsch JE. An index to quantify an individual's scientific research output. Proc Natl Acad Sci U S A. 2005;102(46):16569-72.

2. Carbon CC. The Carbon_h-factor: predicting individuals' research impact at early stages of their career. PLoS One. 2011;6(12):e28770.

3. Susarla SM, Lopez J, Swanson EW, Miller D, O'Brien-Coon D, Zins JE, Serlett $J M$, Yaremchuk MJ, Manson PN, Gordon CR. Are quantitative measures of academic productivity correlated with academic rank in plastic surgery? A national study. Plast Reconstr Surg. 2015;136(3):613-21.

4. Benway BM, Kalidas P, Cabello JM, Bhayani SB. Does citation analysis reveal association between $\mathrm{h}$-index and academic rank in urology? Urology. 2009; 74(1):30-3.

5. Lee J, Kraus KL, Couldwell WT. Use of the $h$ index in neurosurgery. Clinical article. J Neurosurg. 2009:111(2):387-92.

6. Rad AE, Brinjikji W, Cloft HJ, Kallmes DF. The H-index in academic radiology. Acad Radiol. 2010;17(7):817-21.

7. Svider PF, Choudhry ZA, Choudhry OJ, Baredes S, Liu JK, Eloy JA. The use of the h-index in academic otolaryngology. Laryngoscope. 2013;123(1):103-6.

8. Bould MD, Boet S, Sharma B, Shin E, Barrowman NJ, Grantcharov T. Hindices in a university department of anaesthesia: an evaluation of their feasibility, reliability, and validity as an assessment of academic performance. Br J Anaesth. 2011;106(3):325-30.

9. DeLuca LA Jr, St John A, Stolz U, Matheson L, Simpson A, Denninghoff KR. The distribution of the h-index among academic emergency physicians in the United States. Acad Emerg Med Off J Soc Acad Emerg Med. 2013;20(10): 997-1003.

10. Gast KM, Kuzon WM Jr, Adelman EE, Waljee JF. Influence of training institution on academic affiliation and productivity among plastic surgery faculty in the United States. Plast Reconstr Surg. 2014;134(3):570-8.

11. Lopez J, Susarla SM, Swanson EW, Calotta N, Lifchez SD. The association of the H-index and academic rank among full-time academic hand surgeons affiliated with fellowship programs. J Hand Surg. 2015;40(7):1434-41.

12. Paik AM, Mady LJ, Villanueva NL, Goljo E, Svider PF, Ciminello F, Eloy JA. Research productivity and gender disparities: a look at academic plastic surgery. J Surg Educ. 2014;71(4):593-600.

13. Khan NR, Thompson CJ, Taylor DR, Venable GT, Wham RM, Michael LM 2nd, Klimo P Jr. An analysis of publication productivity for 1225 academic neurosurgeons and 99 departments in the United States. J Neurosurg. 2014; 120(3):746-55

14. Babineau M, Fischer C, Volz K, Sanchez LD. Survey of publications and the $\mathrm{H}$-index of academic emergency medicine professors. West J Emerg Med. 2014;15(3):290-2.

15. Sharma B, Boet S, Grantcharov T, Shin E, Barrowman NJ, Bould MD. The hindex outperforms other bibliometrics in the assessment of research performance in general surgery: a province-wide study. Surgery. 2013;153(4): 493-501.

16. Pagel PS, Hudetz JA. An analysis of scholarly productivity in United States academic anaesthesiologists by citation bibliometrics. Anaesthesia. 2011; 66(10):873-8.

17. Spearman CM, Quigley MJ, Quigley MR, Wilberger JE. Survey of the $h$ index for all of academic neurosurgery: another power-law phenomenon? J Neurosurg. 2010;113(5):929-33.
18. Choi $M$, Holliday EB, Jagsi R, Wilson LD, Fuller CD, Thomas CR Jr. Citationbased estimation of scholarly activity among domestic academic radiation oncologists: five-year update. J Radiat Oncol. 2014;3(1):115-22.

19. Rezek I, McDonald RJ, Kallmes DF. Is the h-index predictive of greater NIH funding success among academic radiologists? Acad Radiol. 2011;18(11): 1337-40.

20. Poynard T, Thabut D, Munteanu M, Ratziu V, Benhamou Y, Deckmyn O. Hirsch index and truth survival in clinical research. PLoS One. 2010;5(8): e12044.

21. McIntyre KM, Hawkes I, Waret-Szkuta A, Morand S, Baylis M. The H-index as a quantitative indicator of the relative impact of human diseases. PLoS One. 2011;6(5):e19558.

22. Turaga KK, Gamblin TC. Measuring the surgical academic output of an institution: the "institutional" H-index. J Surg Educ. 2012;69(4):499-503.

23. Bartneck C, Kokkelmans $S$. Detecting h-index manipulation through selfcitation analysis. Scientometrics. 2011;87(1):85-98.

24. Ouimet M, Bedard PO, Gelineau F. Are the h-index and some of its alternatives discriminatory of epistemological beliefs and methodological preferences of faculty members? The case of social scientists in Quebec. Scientometrics. 2011;88(1):91-106.

25. Tijdink JK, Vergouwen AC, Smulders YM. Emotional exhaustion and burnout among medical professors; a nationwide survey. BMC Med Educ. 2014;14:183,

26. Mimouni M, Zayit-Soudry S, Segal O, Barak Y, Nemet AY, Shulman S, Geffen $\mathrm{N}$. Trends in authorship of articles in major ophthalmology journals by gender, 2002-2014. Ophthalmology. 2016;123(8):1824-8.

\section{Publisher's Note}

Springer Nature remains neutral with regard to jurisdictional claims in published maps and institutional affiliations.
Ready to submit your research? Choose BMC and benefit from:

- fast, convenient online submission

- thorough peer review by experienced researchers in your field

- rapid publication on acceptance

- support for research data, including large and complex data types

- gold Open Access which fosters wider collaboration and increased citations

- maximum visibility for your research: over $100 \mathrm{M}$ website views per year

At BMC, research is always in progress.

Learn more biomedcentral.com/submissions 